\title{
Detection of Inducible and Non-inducible (constitutive) AmpC $\beta$-lactamase- producing Gram-Negative Bacteria among Family Enterobacteriaceae by Two Phenotypic Methods-Disk Antagonism Test (DAT) and AmpC disk Test at a Tertiary Care Hospital, Himachal Pradesh, India
}

\author{
A. K. Ashok*, S. C. Jaryal, K. Thakur, A. Sood, P. K. Gupta, and S. Thakur \\ Department of Microbiology, Dr. Rajendra Prasad Govt. Medical College Kangra at Tanda, \\ Himachal Pradesh, India \\ *Corresponding author
}

\section{A B S T R A C T}

Keywords

AmpC $\beta$ -

lactamase,

cefoxitin

screening,

cefoxitin sensitive,

cefoxitin resistant,

Disk antagonism

test,

AmpC disk test.

\section{Article Info}

Accepted:

10 March 2016

Available Online:

10 April 2016
Gram-negative bacilli particularly among family Enterobacteriaceae produce AmpC $\beta$ lactamases which are often responsible for multidrug resistance. Their detection is problematic in routine as there are no Clinical Laboratory Standards Institute (CLSI) or other approved criteria for screening and detection of AmpC $\beta$-lactamases. So, it is a matter of great concern. Also only some studies have shown a few phenotypic methods which are comparatively easy and cheap. There has not been done such study in our state Himachal Pradesh. So it was decided to perform such types of studies at our institute. Aims \& Objectives: To detect inducible and non-inducible (constitutive) AmpC $\beta$-lactamases by Disk Antagonism Test (DAT) and AmpC Disk methods. Material and Methods: Out of total 9105 clinical samples received in the Department of Microbiology for culture and sensitivity, 1200 samples were identified by colony morphology, Gram staining and Biochemical reactions as belonging to family Enterobacteriaceae. These samples were isolated from urine, pus, blood, and others. These isolates were screened by cefoxitin disk test. Those organisms sensitive to cefoxitin disc test were subjected to Disk antagonism test (DAT) \& those resistant to it were subjected to AmpC disk test. Results: Of the 1200 isolates 575 were cefoxitin sensitive and 625 were cefoxitin resistant. Of 625 cefoxitinresistant isolates, $48(4.0 \%)$ isolates were found to be positive for AmpC $\beta$-lactamase production by the phenotypic method AmpC disc test. Out of 575 cefoxitin sensitive strains, $28(4.87 \%)$ revealed the presence of inducible AmpC $\beta$-lactamase by Disk antagonism test. Conclusions: The test DAT to know inducible AmpC $\beta$-lactamase and AmpC disk test to know plasmid-mediated AmpC $\beta$-lactamase is simple, less time consuming as well as cost effective and has a reliable approach.

\section{Introduction}

$\beta$-lactamases are heterogeneous bacterial enzymes that cleave the $\beta$-lactam ring of penicillins and cephalosporins to inactivate the antibiotic. (Allen et al., 2006) Extended spectrum $\beta$-lactamases (ESBLs) are enzymes that mediate resistance to third generation cephalosporins (3 GCs) and monobactams (aztreonam) but do not affect cefamycins (cefoxitin, cefotetan, etc) or carbapenems (imipenem, meropenem, ertapenem, doripenem etc.). They are inhibited by $\beta$-lactamase inhibitor 
combinations (BLIs) such as clavulanic acid, sulbactam and tazobactam. Therefore, any strain resistant to $3 \mathrm{GC}$ but sensitive to $\beta$ lactam $/ \beta$-lactam inhibitor combination (BL/BLI) is likely to contain ESBL. (Paterson and Bonomo, 2005) AmpC class $\beta$-lactamases (AmpC) are cephalosporinases which are not inhibited by clavulanic acid, tazobactam \& sulbactam. They degrade penicillins, monobactams, and $\beta$-lactam inhibitors. (Jacoby, 2009) There are 2 types of classifications of $\beta$-lactamases. According to Bush-Jacoby-Medeiros functional classification, AmpCs belong to Group1 and according to Ambler Structural / Molecular classification they belong to Class C. (Bush et al., 1995)

Production of $\beta$-lactamase is the most common mechanism of antibiotic resistance among Gram-negative bacilli. Among the $\beta$ lactamases, the most common is production of ESBLs and AmpCs. (Coudron et al., 2000) AmpC $\beta$-lactamase production is frequently accompanied by multidrug resistance. Resistance caused by plasmidmediated AmpC $\beta$-lactamase is less common than the production of ESBLs, but may be more difficult to detect. (Hsieh et al., 2015)

AmpC $\beta$-lactamases are of two types: Plasmid-mediated and Chromosomalmediated. The chromosomally mediated $\beta$ lactamase production takes place mainly through the expression of the AmpC gene which is either constitutive or inducible. In most of the genera of the family Enterobacteriaceae, AmpC is inducible. The plasmid-mediated AmpC enzymes except for DHA enzymes are almost always expressed constitutively. ${ }^{4}$ Majority of AmpC $\beta$-lactamases are chromosomally mediated (unlike ESBLs which are plasmidmediated). In general, plasmid-encoded AmpC beta-lactamases are expressed constitutively. Plasmid-mediated AmpC $\beta$ lactamases have arisen through transfer of chromosomal gene for AmpC $\beta$-lactamases on to the plasmid. (Akhter, 2015) Chromosomal AmpC beta-lactamases are usually inducible, while, except for DHA (Docosahexanoic acid) enzymes, plasmidmediated AmpC enzymes are uninducible.

The detection of AmpCs is important as they are concerned with treatment failure \& their prevalence is increasing worldwide. The detection of AmpC production can be done by phenotypic and molecular methods. Different phenotypic AmpC detection tests have been described in the literature. Enzyme extraction methods have traditionally been cited as the optimum phenotypic detection method for AmpC activity. However, these are labour-intensive and not suitable for routine clinical use. Inhibitors of the AmpC enzyme are well described and include boronic acid compounds, cloxacillin, and novel inhibitors such as Syn2190. (Manual of workshop on detection of beta-lactamases, 2011) The use of disk approximation tests by Kirby-Bauer testing to detect inducible AmpC activity has also been described, using one antibiotic as an inducing substrate and a second antibiotic as a reporter substrate. A standard test for the detection of the plasmidmediated AmpC enzyme is necessary. The phenotypic tests done namely Disk antagonism test (DAT) and AmpC Disk test were comparatively easier, cheaper and could readily be done in even small set up. Molecular techniques like Polymerase chain reaction (PCR) are costly and not available in every set up.

\section{Materials and Methods}

The present cross sectional study was conducted in the Microbiology department of tertiary care centre Dr. Rajendra Prasad 
Govt. Medical College Kangra at Tanda located in foothills of Northern Himalayan region of India. The study was conducted over a period of one year from March 2014 to April 2015.All the clinical samples processed during this period and isolates identified as a member of family Enterobacteriaceae were included in the study. All the clinical isolates were identified using standard microbiological procedures. (Allen et al., 2006)

The isolates were subjected to cefoxitin disk test as a screening test. (Chaudhary et al., 2008) Briefly, the isolates with zone diameter $\geq 18 \mathrm{~mm}$ were considered sensitive and those less than $18 \mathrm{~mm}$ as resistant. DAT test was performed on cefoxitin isolates while AmpC disc test was performed on cefoxitin resistant isolates. DAT test was done by the methods of Sanders et al. (Manual of workshop on detection of betalactamases, 2011) Briefly, the test isolate was exposed to disks of ceftazidime $(30 \mu \mathrm{g})$ and imipenem $(10 \mu \mathrm{g})$ placed $20 \mathrm{~mm}$ apart (edge to edge) as shown in figure-1. It was incubated at $37^{\circ} \mathrm{C}$ for $18-24$ hours. After overnight incubation flattening of the radius of the zone of inhibition around ceftazidime disk when produced indicated inducible AmpC production by the isolate.

For AmpC disk test a lawn culture of Escherichia coli ATCC 25922 was prepared on Mueller-Hinton agar plate as shown in figure-2. Sterile disk $(6 \mathrm{~mm})$ moistened with $20 \mu 1$ Normal Saline was inoculated with several colonies of test organism. Inoculated disk was placed almost touching the cefoxitin disk $(30 \mu \mathrm{g})$ on the plate. It was incubated at $37^{\circ} \mathrm{C}$ for 18-24 hours. (Coudron, 2005) Afterovernight inoculation at $37^{\circ} \mathrm{C}$, a positive test appeared as flattening or indentation of the zone of inhibition around the cefoxitin disk.

The study was approved by institutional ethical committee, Dr Rajendra Prasad Government Medical College \& Hospital (DRPGMCH), Kangra at Tanda (Himachal Pradesh).

\section{Results and Discussion}

During one year period 9105 clinical samples were processed and 1200 bacterial isolates were identified as a member of family Enterobacteriaceae in 1094 samples (there were more than one bacterial isolates in some sample). The maximum number of samples were from urine 548(50.09\%) followed by pus $382(34.92 \%)$ and blood $74(6.76 \%)$. Other samples included were sputum, endocervical swab, endotracheal tube, aural swab, anal swab, CVP line, tissue, stool, throat swab, cerebrospinal fluid (CSF), catheter tip, BM aspirate, ascitic fluid, pleural fluid, bronchoalveolar lavage, prostatic secretion. Different isolates were E.coli (66.08\%) maximally followed by Klebsiella species (11.33\%), Citrobacter species (10.17\%), Enterobacter species (5.34\%), Proteus species (3.50\%), Salmonella typhi (1.08\%), Pantoea agglomerans (1.00\%), Morganella morganii $(0.75 \%)$ and Providencia species $(0.58 \%)$.Other species include Serratia marcescens (1) and Salmonella paratyphi A(1).E. coli followed by Klebsiella species were maximally isolated from urine. The maximum number of organisms isolated from pus and blood were E.coli followed by Citrobacter spp.

The screening test using cefoxitin disc $(30 \mu \mathrm{g})$ was sensitive in $47.92 \%(575 / 1200)$ of isolates and resistant in $52.08 \%$ $(625 / 1200)$ of the isolates. Out of 1200 isolates, 48 (4\%) were non-inducible AmpC producers shown by AmpC disk test. Similarly, out of 1200 bacterial isolates, 28 $(2.33 \%)$ were inducible as shown by DAT.

Antimicrobial drug resistance is emerging 
worldwide as a major public health problem.Misuse and overuse of antibiotics has resulted in the emergence and dissemination of resistant bacteria.There are many mechanisms of antibiotic resistance. AmpC $\beta$-lactamase production is one of the mechanisms of antibiotic resistance. The production of AmpC $\beta$-lactamase is mainly chromosomally mediated and also plasmidmediated (Carmeli et al., 1999; Cavallo et al., 2002; Livermore, 2002).

AmpC detection is not routinely carried out in many microbiology laboratories. This could be due to lack of awareness, resources or facilities. This study was planned with a view to find the proportion of $\mathrm{AmpC} \beta$ lactamases in various clinical isolates belonging to family Enterobacteriaceae and also to detect inducible (chromosomal) and Plasmid mediated AmpC $\beta$-lactamases by two phenotypic methods. In all these AmpC producers, we were not able to distinguish between the chromosomal and plasmid mediated enzymes, as this requires genotypic confirmatory tests. (Yilmaz et al., 2007; Doi and Paterson, 2007)

Figure.1.Disk Antagonism Test (DAT)

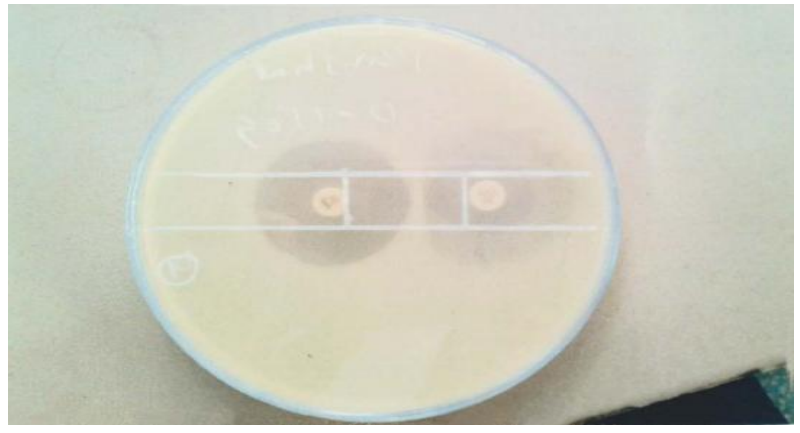

Figure.2 AmpC Disk Test

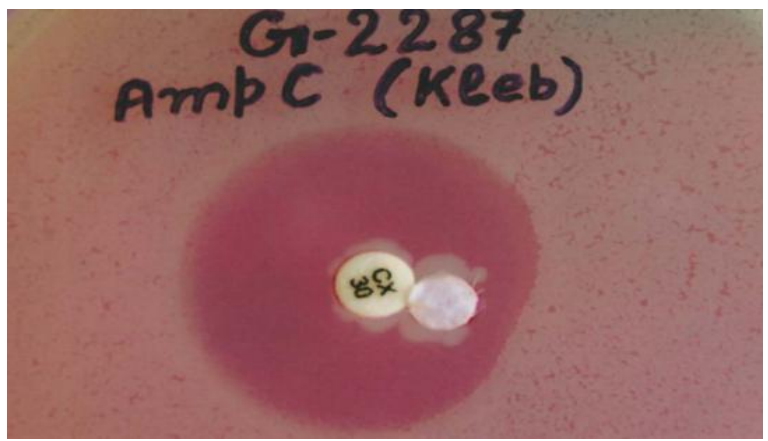

In most genera of the family Enterobacteriaceae AmpC is inducible. Plasmid-mediated inducible beta-lactamases are extremely rare. (Parveen et al., 2010) In this study $2.33 \% \quad(28 / 1200)$ were chromosomally-mediated (inducible) while $4 \% \quad(48 / 1200) \quad$ plasmid-mediated (uninducible). In a study by Nasir et al at Jaipur $2.2 \%(7 / 320)$ were chromosomallymediated. (Nasir et al., 2015) In a study at Egypt by Wassef $\mathrm{M}$ and Behiry I $86.4 \%$ (19/22) were chromosomally-mediated and $13.6 \%$ ( 3/22) plasmid-mediated AmpC. (Wassef et al., 2014) Amongst the 320 
urinary Enterobacteriaceae isolates the inducible AmpC production was maximally detected by the ceftazidime-imipenem disk antagonism test $(3.1 \%)$ and the noninducible isolates by AmpC disk test (2.2\%). (Shevade and Agarwal, 2013) Cefoxitin and imipenem are strong inducers of the AmpC $\beta$-lactamases, whereas cefotaxime and ceftazidime are weak inducers.

In Gram-negative bacteria belonging to family Enterobacteriaceae, AmpC betalactamase production is chromosomal or plasmid-mediated. In our study E.coli, Klebsiella spp., Proteus spp, Salmonella Typhi and Citrobacter spp. were chromosomal. E.coli, Klebsiella spp, Citrobacter spp and Enterobacter spp. were plasmid-mediated. Chromosomal AmpC is less in prevalence in comparison to plasmid mediated. (Barlow and Hall, 2002; Johnson, and O'Bryan, 2000; Thomson, 2010) In our study prevalence of chromosomal AmpC was $2.33 \%(28 / 1200)$ in comparison to 4.00 $\%(48 / 1200)$ plasmid mediated. This is statistically significant at $\mathrm{p}<0.05(0.019734)$. Various studies have shown different prevalence of AmpC producers among different organisms. This geographical difference may be due to different patterns of antibiotic use and difference in the selection of organisms for the study.

Given the need for a test for AmpC $\beta$ lactamases and the fact that many clinical laboratories are often short staffed and overworked, the AmpC disk test could fill a current gap in diagnostic microbiology. Adoption of this test would make it possible to learn more about the clinical implications of plasmid-mediated AmpC $\beta$-lactamases and to contain the spread of organisms possessing this resistance mechanism. The potential benefits would include better patient outcomes in terms of avoiding in appropriate therapy and a reduction in the escalation of antibiotic resistance through better infection control.

There was not gold standard test in our study. So the diagnostic accuracy and efficiency of combination of tests was not evaluated by sensitivity and specificity analysis. Phenotypic confirmation tests are inexpensive but nevertheless highly sensitive and specific (confirmed in another studies). (Peter-Getzlaff et al., 2011)

In this study, the number of AmpC producing Enterobacteriaceae isolates which were studied was less. Hence, further studies with more number of strains are needed. Also there is need of confirmatory phenotypic tests like Cloxacillin combined disk diffusion test (CCDDT) and molecular methods like PCR.

In conclusion, Phenotypic AmpC screening and confirmation tests are inexpensive but nevertheless highly sensitive and specific. Therefore, it can be performed in all types of clinical laboratories, whereas the implementation of molecular methods is often complex, requires specially trained personnel, and is associated with higher costs.

\section{References}

Akhter, S. 2015. Prevalence and Detection of AmpC $\beta$-Lactamases in Gram Negative Bacilli from BIHS Hospital, Mirpur, Dhaka. Int. J. Res. Studies in Microbiol. Biotechnol., (IJRSMB) 2: 1-6.

Barlow, M., Hall, B.G. 2002. Origin and evolution of the AmpC betalactamases of Citrobacter freundii. Antimicrob.Agents Chemother., 46: 1190-1198.

Bush, K., Jacoby, G.A., Medeiros, A.A. 1995. A functional classification scheme for beta-lactamases and its 
correlation with molecular structure. Antimicrob. Agents Chemother., 39: 1211-1233.

Carmeli, Y., Troillet, N., Eliopoulos, G.M., Samore, M.H. 1999. Emergence of antibiotic-resistant Pseudomonas aeruginosa: comparison of risks associated with different antipseudomonal agents. Antimicrob. Agents Chemother., 43: 1379-1382.

Cavallo, J.D., Plesiat, P., Couetdic, G., Leblanc, F., Fabre, R. 2002. Mechanisms of $\beta$-lactam resistance in Pseudomonas aeruginosa: prevalence of OprM-overproducing strains in a French multicentre study (1997). J. Antimicrob. Chemother., 50: 1039-1043.

Chaudhary, U., Aggarwal, R., Ahuja, S. 2008. Detection of Inducible AmpC $\beta$-Lactamase-Producing GramNegative Bacteria in a Teaching Tertiary Care Hospital in North India. J. Infect. Dis. Antimicrob. Agents, 25: 129-133.

Coudron, P.E., Moland, E.S., Thomson, K.S. 2000. Occurrence and detection of AmpC beta-lactamases among Escherichia coli, Klebsiella pneumoniae and Proteus mirabilis isolates at a veteran medical centre. J. Clin. Microbiol., 38: 1791-1796.

Coudron. 2005. PE Inhibitor-based methods for detection of plasmid-mediated AmpC beta-lactamases in Klebsiella spp., Escherichia coli and Proteus mirabilis. J. Clin. Microbiol., 43: 4163-4167.

Doi, Y., Paterson, D.L. 2007. Detection of plasmid-mediated class $\mathrm{C}$ betalactamases. Int. J. Infect. Dis., 11: 191-197.

Hsieh, W.S., Wang, N.Y., Feng, J.A., Weng, L.C., Wu, H.H. 2015. Identification of DHA-23, a novel plasmidmediated and inducible AmpC beta- lactamase from Enterobacteriaceae in Northern Taiwan. Front Microbiol., 6: 436.

Jacoby, G.A. 2009. AmpC beta-lactamases. Clin. Microbiol. Rev. 22: 161-82.

Johnson, J.R., O'Bryan, T.T. 2000. Improved repetitive-element PCR fingerprinting for resolving pathogenic and nonpathogenic phylogenetic groups within Escherichia coli. Clin.Diagn. Lab. Immunol., p. 7265-73

Jr. WN, Allen, S., Janda, W., Koneman, E., Procop, G., Schreckenberger, et al. editors. 2006. The Enterobacteriaceae. Koneman's Color Atlas and Textbook of Diagnostic Microbiology, 6th ed. San Francisco: Lippincott, p. 211302.

Jr.WN, Allen, S, Janda, W., Koneman, E., Procop, G., Schreckenberger, et al., editors. 2006.2 The Enterobacteriaceae. Koneman's Color Atlas and Textbook of Diagnostic Microbiology, 6th ed. San Francisco: Lippincott, p.996.

Livermore, D.M., Struelensm M., Amorim, J., Baquero, F., Bille, J., Canton, R., et al. 2002. Multicentre evaluation of the VITEK 2 Advanced Expert System for interpretive reading of antimicrobial resistance tests. $J$. Antimicrob. Chemother., 49: 289300.

Manual of workshop on detection of betalactamases. 2011. Phenotypic and genotypic methods Organized by Department of Microbiology, Institute of Medical Sciences, Banaras Hindu University, Varanasi in Xxxv National Conference of Indian Association of Medical Microbiologists, Microcon, Varanasi.

Nasirm, K.M., Preeti, S., Vikili, C., Singh, 
N.P. 2015. Prevalence of ESBL and AmpC $\beta$-Lactamase in Gram Negative Bacilli in various Clinical Samples at Tertiary Care Hospital. Int. Res. J. Med. Sci., 3: 1-6.

Parveen, R.M., Harish, B.N., Parija, S.C. 2010. AmpC Beta Lactamases Among Gram Negative Clinical Isolates From A Tertiary Hospital, South India. Braz. J. Microbiol., 41: 596-602.

Paterson, D.L., Bonomo, R.A. 2005. Extended spectrum beta lactamases: a clinical update. Clin. Microbiol. Rev., 18: 657-686.

Peter-Getzlaff, S., Polsfuss, S., Poledica, M., Hombach, M., Giger, J., Böttger, E.C., et al. 2011. Detection of AmpC beta-lactamase in Escherichia coli: comparison of three phenotypic confirmation assays and genetic analysis. J. Clin. Microbiol., 49:
2924-32.

Shevade, S.U., Agarwal, A. 2013. Study on the AmpC Production Amongst the Urinary Enterobacteriaceae Isolates. J. Clin. Diagn. Res., 7: 1831-1832.

Thomson, K.S. 2010. Extended-spectrumbeta-lactamase, AmpC, and Carbapenemases issues. J. Clin. Microbiol., 48: 1019-25.

Wassef, M., Behiry, I., Younan, M.E., Guindy, N., Mostafa, S., Abada, E., Jundishapur. 2014. Genotypic Identification of AmpC $\beta$ Lactamases Production in GramNegative Bacilli Isolates. $J$. Microbiol., 71: e8556.

Yilmaz, N.O., Agus, N.O., Bozcal, E., Oner, O., Uzel, A. 2007. Detection of plasmid-mediated AmpC $\beta$ lactamase in Escherichia coli and Klebsiella pneumoniae. Indian $J$. Med. Microbiol., 31: 53-59.

\section{How to cite this article:}

Ashok, A.K., S.C. Jaryal, K. Thakur, A. Sood, P.K. Gupta, Thakur, S. 2016. Detection of Inducible and Non-inducible (constitutive) AmpC $\beta$-lactamase-producing Gram-Negative Bacteria among Family Enterobacteriaceae by Two Phenotypic Methods-Disk Antagonism Test (DAT) and AmpC disk Test at a Tertiary Care Hospital, Himachal Pradesh, India. Int.J.Curr.Microbiol.App.Sci. 5(4): 133-139. doi: http://dx.doi.org/10.20546/ijcmas.2016.504.018 